\title{
Cardiac diverticulum
}

INSERM

\section{Source}

INSERM. (1999). Orphanet: an online rare disease and orphan drug data base. Cardiac diverticulum. ORPHA:1686

Congenital cardiac diverticulum (CCD) is a very rare congenital malformation characterized by a muscular appendix emerging from the left ventricular apex, rarely from the right ventricle or from both chambers, with clinical manifestations ranging from asymptomatic to life-threatening hemodynamic collapse. 